\title{
Relationships between Parent-Adolescent Communication, Acculturation, and Sexual Knowledge on Latino Adolescent Sexual Behavior: A Systematic Review
}

\author{
Vanessa Pirani Gaioso ${ }^{1}$, Lynda Law Wilson ${ }^{1}$, Antonia Maria Villarruel ${ }^{2} \&$ Gwendolyn Denice Childs $^{1}$ \\ ${ }^{1}$ School of Nursing, University of Alabama at Birmingham, Birmingham, AL, United States \\ ${ }^{2}$ School of Nursing, University of Pennsylvania, Philadelphia, USA \\ Correspondence: Vanessa Pirani Gaioso, School of Nursing, University of Alabama at Birmingham, $17202^{\text {nd }}$ \\ Ave S., LRC155, Birmingham, AL, USA 35294-1210. Tel: 205-996-9608. E-mail: vgaioso@uab.edu
}

Received: May 15, 2017

doi:10.20849/ijsn.v2i1.146
Accepted: May 31, 2017

Online Published: June 9, 2017

\begin{abstract}
Latino adolescents in the United States are more likely to engage in early and risky sexual behavior compared to adolescents from other racial and ethnic groups. The quantity and quality of parent-adolescent sexual communication has been suggested as the best predictor on adolescent sexual behavior. Method: A systematic literature review of studies was conducted with relationships between selected parental, adolescent and cultural variables and Latino adolescents' intentions to engage in sexual behavior, derived from the Parent-Based Expansion of the Theory of Planned Behavior (PETPB). Results: From 20 studies reviewed, only 12 reported findings specifically to Latinos living in the United States. There was consistency across these studies supporting the relationships between adolescents' attitudes, subjective norms, and self-efficacy toward risky sexual behavior and adolescents' intentions to have sexual intercourse and to use condoms. However, few studies examined any predictors of parent-adolescent sexual communication guided by the PETPB that included psychological factors and antecedent factors. Conclusion: Future studies should be longitudinal and should include a larger sample of Latino with more variation in levels of acculturation in order to generalize the findings to the diverse Latino immigrant population living in the United States.
\end{abstract}

Keywords: theory of planned behavior, Latino adolescent sexual behavior, parent-adolescent sexual communication, Latino cultural variables

\section{Introduction}

In 2014, Hispanics or Latinos comprised $17 \%$ of the population in the United States (U.S.), and the percentage is projected to increase to $29 \%$ by the year 2060 (Colby \& Ortman, 2014). The U. S. Census Bureau defines "Hispanic or Latino Ethnicity" as referring to persons "of Cuban, Mexican, Puerto Rican, South or Central American, or other Spanish culture or origin regardless of race" (U.S. Census Bureau, 2017). Latino adolescents in the U.S. are more likely to engage in early and risky sexual behavior compared to adolescents from other racial and ethnic groups, creating a potentially serious public health problem. Studies show, for example, that since 1995 Latino adolescents in the U.S. between the ages of 15 and 19 years have had the highest teen birth rates of any ethnic group (Martin et al., 2012), and that Latino adolescents are more likely to initiate early sexual activity and avoid using condoms and birth control (Centers for Disease Control and Prevention, 2014). In 2010, the birth rate for Hispanic girls ages 15-19 years was 55.7/1000, compared to 23.5/1000 for non-Hispanic white girls of this age (Martin et al., 2012).

There is growing interest in examining factors that influence parent-adolescent sexual communication, as well as the relationships between communication patterns and risky adolescent sexual behaviors. The Parent-Based Expansion of the Theory of Planned Behavior (PETPB) model (Hutchinson \& Wood, 2007) can be used to guide studies that examine factors that predict risky adolescent sexual behaviors. The PETPB model proposes relationships between external influences on parental behavioral, normative, and control beliefs which in turn influence parental intentions to talk with their adolescents about sex. The PETPB model further proposes that parental intentions to talk with adolescents about sex influence adolescent behavioral, normative and control beliefs, which ultimately influence adolescent sexual intentions and behaviors. Three potentially important 
external influences are the parents' levels of acculturation (Ortega, 2010), perceived value of familism (Benavides, 2007; Gaioso et al., 2015; Ortega, Huang \& Prado, 2012), and levels of knowledge about pregnancy and sexually transmitted diseases (STD; Gaioso et al., 2015; Gallegos, Villarruel, Gómez, Onofre \& Zhou, 2007; Guilamo-Ramos, Jaccard, Dittus \& Bouris, 2006b).

The purpose of this paper is to present a systematic review of studies that address relationships between selected parental, adolescent and cultural variables and Latino adolescents' intentions to engage in sexual behavior, derived from the PETPB model.

\section{Method}

The review was based on the steps described by Whittemore and Knafl (2005). The first step involves identifying the problem for study. The problem for this review was to synthesize previous research that addressed relationships between selected parenting variables and Latino adolescent sexual behavior predicted by the PETPB. The specific relationships that were included: (1) relationships between parent Latino acculturation, familism, and knowledge about pregnancy/ STD/AIDS with their attitudes, subjective norms, and self-efficacy toward sexual communication with their adolescent; (2) relationships between parents' attitudes, subjective norms, and self-efficacy toward sexual communication with parent-adolescent sexual communication; (3) relationship between parents' intentions to talk about sexual behavior and parent-adolescent communication; (4) relationships between adolescent Latino acculturation, familism, and knowledge about pregnancy/STD/AIDS and adolescents' attitudes and subjective norms regarding sexual communication with parents; (5) relationships between adolescents' attitudes and subjective norms regarding sexual communication with parents and parent-adolescent communication; (6) relationships between parent-adolescent sexual communication and adolescents' attitudes and subjective norms toward having sex in the next 3 months, and self-efficacy toward avoiding risky sexual behavior; and (7) relationships between adolescents' attitudes and subjective norms toward having sex in the next 3 months, and self-efficacy about avoiding risky sexual behavior and adolescents' intentions to have sex in the next 3 months (See Figure 1).

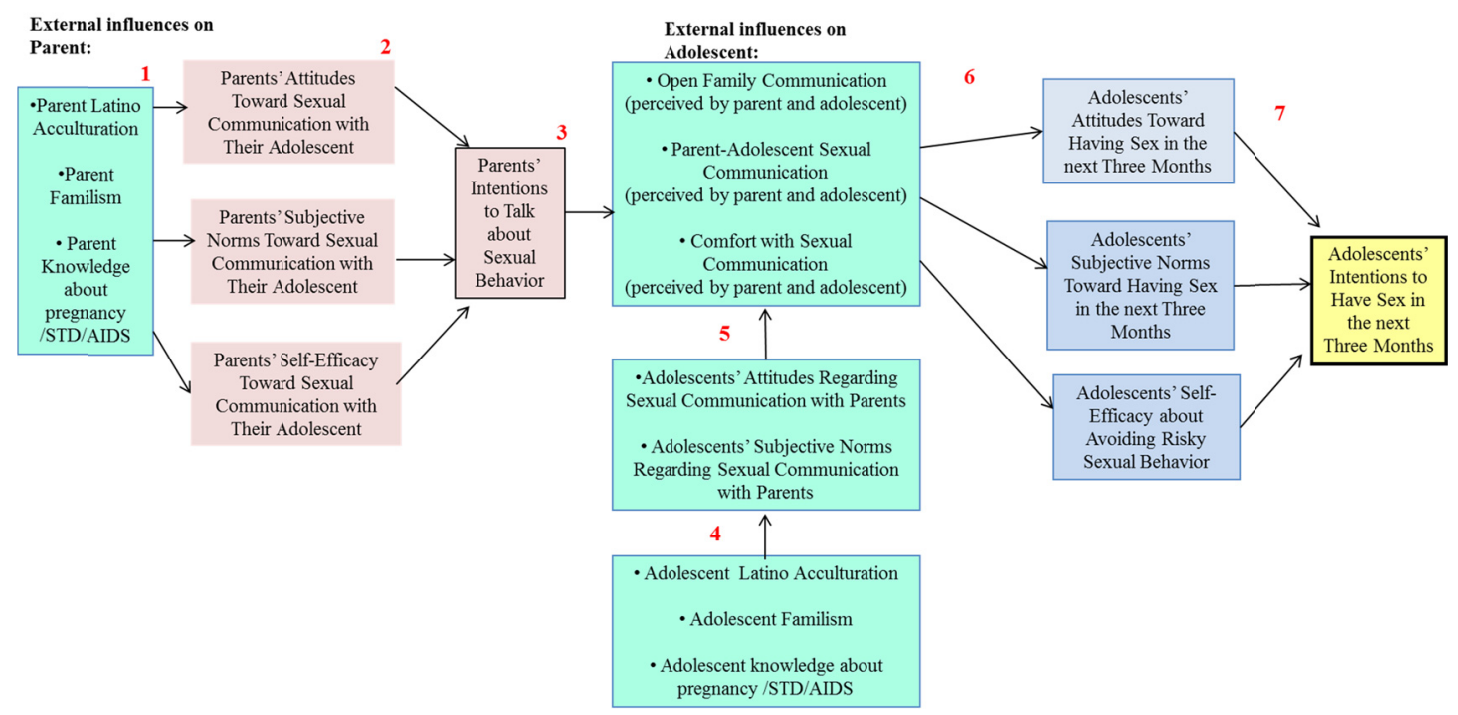

Figure 1. Influences on Latino Adolescent Sexual Behaviors Predicted by the PETPB Model (Gaioso et al., 2015, Hutchinson \& Wood, 2007)

The second step in the Whittemore and Knafl (2005) approach to a systematic review is to identify search strategies to be used. In order to be included in the review, studies or systematic reviews had to (a) focus on one or more of the relationships identified in the PETPB that are summarized in Figure 1; (b) include Latino adolescents (between 10 and 22 years of age) or parents in the sample; (c) be published in a peer-reviewed journal in English or Spanish; (d) be based on empirical research or systematic reviews using quantitative or qualitative methods; and (e) be published between years of 1998 and 2016. Studies conducted outside of the United States were included if they met the above criteria, because of the limited number of studies that addressed some of the relationships of interest for this proposed study. 
A computer-based search of the literature included two databases: PubMed and CINAHL. The keywords were used individually or in combination and encompassed Latino or Hispanic, adolescent, sexual activity, sexual behavior, parent communication, attitudes, norms, self-efficacy, familism, and acculturation. Additional articles were identified from reference lists of the articles.

The final steps in the Whittemore and Knafl (2005) systematic review method include evaluation of the studies' quality, and an analysis, synthesis and presentation of the data. To analyze the quality of the studies, each article was carefully reviewed by two of the authors, and summarized on a table that included methods, findings, and strengths as well as limitations. These assessments were considered during the fourth and fifth phases of the review (analysis and synthesis), and the overall strengths and limitations of the studies are summarized at the end of the paper.

\section{Results}

The review is organized according to the relationships that were included in the PETPB model (Figure 1), with each component noted in parentheses by the subtitle of the section in the review. No studies were identified that examined the relationships in parts 3 or 5 of the PETPB model noted in Figure 1, so those relationships are not included in the review.

3.1 Relationship between Latino Parent Latino Acculturation, Familism, and Sexual Knowledge with Their
Attitudes, Subjective Norms, and Self-Efficacy toward Sexual Communication with Their Adolescent (PETB\#1)

Few studies were found that examined specific relationships between parental levels of acculturation, familism, and sexual knowledge with parents' attitudes, subjective norms, and self-efficacy toward sexual communication with their adolescents. Thus, this review also included studies that examined relationships between the predictors of parent acculturation, parent familism, parent sexual knowledge (including HIV knowledge) with any aspect of parent-adolescent sexual and general communication.

Ortega (2010) surveyed 493 Latino adolescent $7^{\text {th }}$ and $8^{\text {th }}$ graders and their parents residing in Miami. Results indicated that parent levels of orientation toward Anglo culture were negatively correlated with adolescents' perceptions of parent-adolescent communication and adolescent's perceptions of family communication. In addition, the author found no associations between parents' HIV knowledge and adolescents' perceptions of parent-adolescent sexual communication.

Morales-Campos, Markham, Peskin, and Fernandez (2012) examined levels of acculturation and parent-adolescent communication on a sample of 655 Latino seventh graders in southeast Texas. Findings indicated that there were no significant differences between acculturation levels and parent-child communication.

Deutsch and Crockett (2015) examined the associations between Latino acculturation and parent-adolescent sexual messages among 1,944 Latinos (grades 7-11) from the National Longitudinal Study of Adolescent Health data set. Latino acculturation was measured by generational status. First-generation adolescents were classified as foreign-born adolescent, second-generation adolescents were defined as those who were born in the U.S., but primary caregiver was foreign-born, and third-generational adolescents were those who had a U.S.-born primary caregiver and were themselves born in the U.S. Parent-adolescent sexual messages were based on discussions of health consequences, sexual norms, and birth control. Results indicated that third-generation adolescents reported more frequent discussions of health consequences and birth control compared to mothers of first- and second-generation adolescents.

Gallegos et al. (2007) explored differences between parent HIV/AIDS knowledge and parents' perception of general communication, sexual communication, and comfort with sexual communication with their adolescents by parental education level. This study included 829 high school students and one of their parents, residing in Mexico. There were no significant differences in levels of parent HIV/AIDS knowledge and parents' perception of sexual communication and comfort with sexual communication with their adolescent based on parents' education levels.

Benavides (2007) and Gallegos et al. (2007) conducted secondary analyses of data from the study reported Villarruel, Cherry, Cabriales, and Zhou (2008) and examined relationships between familism and parent-adolescent communication. Benavides (2007) found that parents' levels of familism were positively associated with parents' self-efficacy toward parent-adolescent sexual communication. Villarruel et al. (2008) found that parent familism was not a significant moderator on the outcomes of general communication, risky sexual communication, and comfort with sexual communication. One explanation for the difference in these findings may be that Benavides (2007) was examining a direct relationship between familism and self-efficacy 
towards sexual communication, whereas Villarruel et al. (2008) were evaluating whether familism was a moderator on an intervention that measured general communication, risky sexual communication, and comfort with sexual communication.

One qualitative study was identified that focused on exploring parents' perceptions of sexual communication with their adolescents. Guilamo-Ramos et al. (2006a) conducted focus groups to explore the content and process of mother-adolescent sexual communication with 63 Latino mother-adolescent pairs residing in New York City. Mothers reported that they were uncomfortable or embarrassed discussing specific topics related to intercourse and contraception with their adolescents. Mothers suggested that discussions with their adolescents about sex would be facilitated if they had more knowledge about sexual topics.

Findings from the limited number of studies exploring relationships between Latino acculturation or familism and parent/adolescent communication were mixed. One study reported a negative association between parental Anglo acculturation and Latino adolescents' perceptions of family communication (Ortega, 2010). However, Deutsch and Crockett (2015) found that third-generation adolescents reported higher levels of sexual communication to mothers of first- and second-generation adolescents; and Morales-Campos and colleagues (2007) found no such relationships. Similarly, Benavides (2007) reported a positive relationship between parental levels of familism and parents' self-efficacy toward parent-adolescent sexual communication, whereas Villarruel et al. (2008) found that familism did not moderate intervention effects on general communication, risky sexual communication, and comfort with sexual communication. Two studies reported consistent findings of lack of relationships between parental HIV knowledge and communication variables. One reason for the mixed findings may be differences in characteristics of the samples and the measures used to assess the variables, as well different research methods for analysis.

\subsection{Relationships between Parents' Attitudes, Subjective Norms, and Self-Efficacy toward Sexual Communication with Parent-Adolescent Sexual Communication (PETB\#2)}

Four articles were identified that addressed one or more relationships between parents' attitudes, subjective norms, and self-efficacy toward sexual communication with their adolescents and parent-adolescent sexual communication.

In a sample of 791 Mexican parents of adolescents described previously, Villarruel et al. (2008) found that parents' behavioral beliefs, normative beliefs, and self-efficacy toward parent-adolescent sexual communication were significant mediators on the effect of a parent-adolescent intervention on general communication, sexual communication, and comfort with sexual communication.

In another article, Benavides (2003) found that parents who reported greater levels of self-efficacy toward sexual communication with their adolescent were more likely to transmit information to their adolescent about risky sexual behavior and methods to avoid risky sexual behavior. The sample included 42 parents with adolescents between 14 and 17 years of age, residing in Monterrey, Mexico.

In a subsequent article with 756 parents and adolescents between 14 and 17 years of age, living in Mexico, Benavides (2007) found that parents' perceptions of and comfort with parent-adolescent sexual communication were positively correlated with parents' self-efficacy for parent-adolescent sexual communication and with parents' beliefs toward parent-adolescent sexual communication.

Guilamo-Ramos, Jaccard, Dittus, and Collins (2008a) studied 688 mother-adolescent dyads living in New York, including 528 Latinos. They reported a positive association between mothers' descriptive and injunctive norms and mother-adolescent sexual communication reported by the mothers, but not by adolescents. Descriptive norms were assessed by asking the mothers to report the number of close friends that they thought had talked with their adolescent about not having intercourse. Injunctive norms were assessed by asking the mothers about whether people who are important to them would approve of them talking to their adolescent about not having intercourse. Also, the authors reported positive relationships between different aspects of mothers' self-efficacy regarding sexual communication and mother-adolescent sexual communication reported by mothers and adolescents.

In summary, all four articles reported positive relationships between parents' attitudes, subjective norms, and/or perceived self-efficacy toward sexual communication with adolescent and parent-adolescent sexual communication reported by parents, but only one showed this relationship with adolescent reports of sexual communication (Guilamo-Ramos et al., 2008a). Three studies were conducted with Latinos residing outside of the U.S. (Benavides, 2003, 2007; Villarruel et al., 2008), and one study reported findings combined for Latinos and African Americans (Guilamo-Ramos et al., 2008a). These findings suggest that parental attitudes, norms, 
and self-efficacy should be considered when designing and evaluating interventions for parents and adolescents, although there is a need for further research with diverse groups of Latino parents and adolescents. There is also a need for studies that assess both parent and adolescent perceptions of communication variables.

3.3 Relationship between Adolescent Latino Acculturation, Familism, and Knowledge about Pregnancy/STD/AIDS and Adolescents' Attitudes and Subjective Norms Regarding Sexual Communication with Parents (PETB\#4)

Two studies were identified that examined relationships between adolescent acculturation, familism, knowledge about pregnancy/STD/AIDS, and parent-adolescent sexual communication. Villarruel (1998) conducted ethnographic focus group interviews with 21 mothers and 49 Latina adolescents with mean age of 13 years, living in Detroit and Philadelphia. Both mothers and daughters expressed concordance about the importance of virginity and the desire to delay sexual initiation until after marriage or completion of education. Latina mothers expressed an interest in engaging in sexual communication with their daughters, but indicated that they were uncomfortable talking with their daughters about condom use and birth control.

Benavides (2007) found that adolescents' perceptions of parent-adolescent sexual communication and comfort with sexual communication were positively correlated with adolescents' level of familism values.

Findings from these two studies are consistent with findings previously reported that examined relationships between cultural values and norms and values and parent-adolescent sexual communication. These findings suggest the importance of considering both parental and adolescent familism, acculturation, attitudes and norms when designing programs aimed at promoting parent-adolescent sexual communication and reducing risky adolescent sexual behaviors.

\subsection{Relationships between Parent-Adolescent Sexual Communication and Adolescents' Attitudes, Subjective} Norms, and Self-Efficacy toward Risky Sexual Behavior (PETB\#6)

Five studies were identified that examined the influence of Latino parent-adolescent communication on adolescents' attitudes, subjective norms or self-efficacy toward risky sexual behavior. Romo, Lefkowitz, Sigman, and $\mathrm{Au}$ (2002) conducted an observational study among 55 Latino mothers and their adolescent between 12 and 15 years of age, residing in Los Angeles. One year after the recording of the conversations, adolescents completed surveys rating their sexual experiences, adolescents' perceptions of open communication, and adolescents' attitudes toward premarital sex. Results of path analyses indicated that adolescents who perceived greater open communication reported more conservative attitudes about premarital sex. However, adolescents' reports of open communication were not associated with adolescents' sexual behavior.

Halpern-Felsher, Kropp, Boyer, Tschann, and Ellen (2004) found positive associations between adolescents' perceptions of self-efficacy in communication with parents about sex and boys' condom use. There were no significant relationships between girls' perceptions of self-efficacy in communicating with their parents about sex and their condom use. Male and female adolescents' perceptions of self-efficacy in communicating with parents about sex were not related to their attitudes toward condom use. The sample included 256 adolescents with mean age of 15 years old (only $29 \%$ were Latino).

Hutchinson, Jemmott III, Jemmott, Braverman, and Fong (2003) found that adolescent's perceptions of mother-daughter sexual risk communication were positively associated with condom use self-efficacy and negatively related to the frequency of unprotected intercourse, controlling for age of the adolescents. However, adolescents' attitudes and perceived maternal approval of condom use were not potential mediators between mother-daughter sexual risk communication and unprotected intercourse. Interestingly, adolescent's perceptions of mother-daughter sexual risk communication were not significantly correlated with adolescent attitudes, perceptions of mother's approval, and self-efficacy toward engaging in intercourse. The participants were 219 sexually experienced African American and Latina (32\%) females between 12 and 19 years of age residing in Philadelphia.

Malcolm et al. (2013) found that higher levels of parent-adolescent communication about sex were positively associated with condom use attitudes, parental norms, and control beliefs. The participants included 171 sexually active Latino adolescents living in Miami.

Somers and Ali (2011) studied relationships between a number of parenting variables (including parent-adolescent communication about sex) and adolescent sexual attitudes and behaviors among a sample of 194 African American and Latino adolescents in the $7^{\text {th }}$ and $8^{\text {th }}$ grades. Findings were not reported separately for the Latino and African-American samples. The findings suggested that adolescent attitudes (measured by intentions to avoid pregnancy) were negatively related with father-adolescent communication about sex, 
although there were no statistically significant relationships between adolescent attitudes and mother-adolescent communication. The authors suggested that one interpretation of these findings could be that the adolescents were already curious about or engaging in sex, and thus were seeking more communication with their fathers.

In summary, findings from four studies supported relationships between parent-adolescent sexual communication and lower adolescents' attitudes toward engaging in intercourse (Romo et al., 2002), greater adolescents' condom use self-efficacy (Hutchinson et al., 2003), and greater condom use (Halpern-Felsher et al., 2004; Malcolm et al., 2013). However, Somers and Ali (2011) found no significant relationships between mother-adolescent communication about sex and intention to avoid pregnancy (Somers \& Ali, 2011). The finding reported by Halpern-Felsher et al. (2004) that there were different relationships for boys and girls between perceived self-efficacy in communicating with parents about sex and condom use suggests the need to examine differences in predicted relationships based on adolescent and parent gender.

3.5 Relationship between Adolescents' Attitudes, Subjective Norms, and Self-Efficacy about Avoiding Risky Sexual Behavior and Adolescents' Risky Sexual Behavior (PETB\#7)

Seven studies examined relationships between adolescents' attitudes, subjective norms, and self-efficacy about avoiding risky sexual behavior and adolescents' sexual risk intentions and behaviors. Villarruel, Jemmott, Jemmott, and Ronis (2004) conducted a study in Philadelphia and included 141 Latino adolescents between 12 and 18 years old. Results indicated positive correlations between adolescents' self-reported intentions to have intercourse in the next 3 months and adolescents' favorable attitudes and perceptions of approval of subjective norms regarding engagement in intercourse. Favorable attitudes predicted intentions to have sex, whereas subjective norms were not significant predictors. Intention to use condoms in the next 3 months was also positively correlated with perceptions that important referent others would approve condom use. These authors also reported significant associations between condom use intentions and attitudes subjective norms and self-efficacy toward condom use. These findings supported the Theory of Planned Behavior that attitudes, subjective norms, and control beliefs (i.e., self-efficacy) are predictive of behavioral intentions (condom use).

Buhi and Goodson (2007) conducted a systematic review of 69 studies published between 1996 to 2005 that examined predictors of adolescent sexual behavior and intention. Although this review did not focus exclusively on research with Latino adolescents, several studies included Latinos and the review addressed variables of interest in the PETPB model. Findings from the review suggested that intentions or motivation to have sex were the most stable predictors of adolescent sexual behavior. The second fairly stable predictor of adolescent sexual behavior was adolescents' perceptions of subjective norms (i.e., perception of peers having sex, peers' disapproval of sex, or parental disapproval of engaging in intercourse). Findings from seven studies indicated positive relationships between self-efficacy and avoidance of risky sexual behavior, while five studies revealed no association. The relationship between beliefs/attitudes and sexual behavior was examined in 24 studies, and findings from 12 of these studies indicated that positive or permissive attitudes to have sex were associated with sexual intention and behavior. Findings from five studies indicated that there was no association, and findings from the remaining seven studies were mixed. Interestingly, Buhi and Goodson reported that only 17 of the 69 studies that were reviewed reported evidence of validity of the instruments that were used.

Koniak-Griffin, Lesser, Uman, and Nyamathi (2003) studied 572 female pregnant or parenting adolescents with ages between 14 and 20 years (77\% Latina), recruited in Los Angeles. The findings indicated significant negative associations between intentions to use condoms and unprotected sex, and positive correlations between intentions to use condoms and subjective norms, and intentions to use condoms and self-efficacy about condom use. In the hierarchical regression analysis, only behavioral intentions and subjective norms accounted for a significant amount of variance in unprotected sex.

Koniak-Griffin and Stein (2006) conducted a secondary analysis of data from the Koniak-Griffen et al. (2003) study, and found that intentions to use condoms were direct predictors of more condom use behavior. Adolescents with higher intentions to use condoms at 3-month evaluation reported less unprotected sex at 6-month follow-up evaluation. The authors also found positive association between adolescents' perceptions of parents' approval of condom use and their intentions to use condoms; and a positive association between adolescent condom use self-efficacy and intentions to use condoms.

Prado et al. (2009) found that condom use social norms were not significantly associated with attitudes about sex, social norms regarding sex, or sexual intentions. Also condom use intentions were not correlated with sexual intentions. The authors reported that all other intrapersonal risk factors for sex were significantly correlated, such as social norms regarding sex, attitudes about sex, intentions to have sex, social norms regarding condom use, 
attitudes condoms, and intentions to use condoms. Participants were 254 Latino adolescents with a mean age of 13 years residing in Miami.

Guilamo-Ramos, Jaccard, Dittus, Gonzalez, and Bouris (2008b) interviewed 528 Latino and 140 African American adolescents from New York City, with mean age of 13 years old. One of the variables of this study included behavioral intentions to engage in intercourse and parents' and relatives' injunctive norms (parents' and relatives' approval or disapproval of adolescents' engaging on intercourse) and peers injunctive norms (approval or disapproval by one's close friends). Structural equation modeling results indicated significant path coefficient for adolescents' sexual intentions and peer injunctive norms, but not for parents' and relatives' injunctive norms.

Sneed, Tan and Meyer (2015) conducted a study in Southern California that included 212 adolescents between the ages of 11 to 16 years (28.9\% Latino). Results indicated that self-efficacy in limitating sexual behavior and attitudes toward sex were positevely associated with intentions to have sex. In addition, male adolescents'self-report of being told by parents that they should wait until after marriage to have sex was positively associated with greater intentions to have sex, but this relationship was not significant for girls.

In summary, findings from five studies supported that adolescents' intentions to have sex and condom use are predictors of protected intercourse (Buhi \& Goodson, 2007; Koniak-Griffin et al., 2003; Koniak-Griffin \& Stein, 2006; Prado et al., 2009; Villarruel et al., 2004). Findings from four studies indicated positive relationships between adolescents' perceptions of normative beliefs or subjective norms about condom use and engagement in intercourse and adolescents' intentions to use condoms (Koniak-Griffin et al., 2003; Koniak-Griffin \& Stein, 2006; Villarruel et al., 2004) and adolescents' sexual activity (Buhi \& Goodson, 2007). Findings from three studies indicated positive relationships between adolescents' self-efficacy toward condom use and avoidance of intercourse and adolescents' risky sexual behaviors and condom use intentions (Koniak-Griffin et al., 2003; Koniak-Griffin \& Stein 2006; Villarruel et al., 2004). Villarruel et al. (2004) found that adolescents' favorable attitudes toward abstinence and condom use were significantly associated with adolescents' intentions to use condoms and to abstain from intercourse. Only two studies reported findings specific for Latino adolescents (Prado et al., 2009; Villarruel et al., 2004), and none of the studies compared differences in these relationships among different Latino sub-populations.

\section{Discussion and Conclusion}

Findings across the studies examining relationships between acculturation and parent-adolescent communication were mixed, possibly because of differences in characteristics of the samples and the measures used to assess the variables, as well different research methods for analysis. There was consistency in finding positive relationships between parents' attitudes, subjective norms, and/or perceived self-efficacy toward sexual communication with adolescent and parent-adolescent sexual communication reported by parents, but only one study showed this relationship with adolescent reports of sexual communication. This finding suggests that future studies should examine both parent and adolescent perceptions of parent-adolescent communication. Most studies reviewed supported relationships between parent-adolescent sexual communication and lower adolescents' attitudes toward engaging in intercourse, greater adolescents' condom use self-efficacy, and greater condom use. However, findings from one study (Halpern-Felsher et al., 2004) suggested that these relationships were different for boys and girls. There was consistency across two studies reviewed that reported positive relationships between cultural values and norms and parent-adolescent sexual communication. Finally, there was consistency across studies supporting the relationships between adolescents' attitudes, subjective norms, and self-efficacy toward risky sexual behavior and adolescents' intentions to have intercourse and to use condoms. However, few studies examined any predictors of parent-adolescent sexual communication guided by the PETPB that included psychological factors (e.g., parent-adolescent attitudes, subjective norms, and/or self-efficacy toward parent-adolescent sexual communication) and antecedent factors (e.g., Latino acculturation, familism, knowledge about pregnancy, STD/AIDS).

Only 13 of the 22 articles reviewed reported findings specific to the Latinos in the sample, and 4 of these articles were with Latinos living in Mexico. Limitations identified were that most studies used convenience samples, cross-sectional designs, and assessed only adolescent's reports of parent-adolescent sexual communication. Another limitation of this review is that some articles were secondary data analyses and used the same datasets previously reported (Benavides, 2007; Gallegos et al., 2007; Koniak-Griffin \& Stein, 2006).

\section{Implications for Future Research}

Future studies should be longitudinal to examine how cultural variables and family factors are related to adolescents' sexual intentions over time. Future research should also include a larger sample of Latino mothers and fathers from different countries and with more variation in levels of acculturation in order to generalize the 
findings to the diverse Latino immigrant population living in the U. S. There is also a need for further research that: (a) analyzes data separately for males and females because there may be different relationships between parent-adolescent communication and adolescent sexual behaviors for the two genders; and (b) measures perceptions of communication from both parents and adolescents in studies examining the effects of parent-adolescent communication, because findings from previous study (Gaioso, 2013) indicated that parents tended to perceive the communication more positively than adolescents.

\section{References}

Benavides, R. A. (2003). Comunicacion y creencias sexuales de padres de adolescentes (Master's thesis, Universidad Autónoma de Nuevo León, Monterrey, México). Retrieved from http://cdigital.dgb.uanl.mx/te/1080124373.pdf

Benavides, R. A. (2007). An interaction model of parents' and adolescents' influences on mexican adolescents' intentions for contraception and condom use. Doctoral dissertation, University of Texas at Austin. Retrieved from http://repositories.lib.utexas.edu/bitstream/handle/2152/3465/benavidestorresr52613.pdf?sequence $=2$

Buhi, E. R., \& Goodson, P. (2007). Predictors of adolescent sexual behavior and intention: A theory-guided systematic review. Journal of Adolescent Health, 40(1), 4-21. https://doi.org/10.1016/j.jadohealth.2006.09.027

Centers for Disease Control and Prevention. (2014). Youth Risk Behavior Surveillance - United States 2013. MMWR Surveillance Summaries, 63(4),1-172. Retrieved from http://www.cdc.gov/healthyyouth/yrbs/

Colby, S. L., \& Ortman, J. M. (2014). Projections of the size and composition of the U.S. population: 2014 to 2060, Current Population Reports, p25-1143, U.S. Census Bureau, Washington, DC. Retrieved from https://www.census.gov/content/dam/Census/library/publications/2015/demo/p25-1143.pdf

Deutsch, A. R., \& Crockett, L. J. (2016). Gender, generational status, and parent-adolescent sexual communication: implications for Latino/a adolescent sexual behavior. Journal of Research on Adolescence: the Official Journal of the Society for Research on Adolescence, 26(2), 300-315. https://doi.org/10.1111/jora.12192

Gaioso, V. P. (2013). Relationships between latino parental, adolescent and cultural variables on adolescents' attitudes, norms, self-efficacy, and sexual intentions (Doctoral dissertation, The University of Alabama at Birmingham). Retrieved from ProQuest Dissertations and Theses, 258, http://search.proquest.com/docview/1434877976? accountid=8240. (1434877976).

Gaioso, V.P., Villarruel, A. M., Wilson, L. A., Azuero, A., Childs, G. D., \& Davies, S. (2015). A path analysis of latino parental, teenager and cultural variables in teenagers' sexual attitudes, norms, self-efficacy, and sexual intentions. Revista Latino-Americana de Enfermagem, 23(3), 500-511. https://doi.org/10.1590/0104-1169.0398.2581

Gallegos, E. C., Villarruel, A. M., Gómez, M. V., Onofre, D. J., \& Zhou, Y. (2007). Research brief: sexual communication and knowledge among Mexican parents and their adolescent children. Journal of the Association of Nurses in AIDS Care, 18(2), 28-34. https://doi.org/10.1016/j.jana.2007.01.007

Guilamo-Ramos, V., Dittus, P., Jaccard, J., Goldberg, V., Casillas, E., \& Bouris, A. (2006a). The content and process of mother adolescent communication about sex in Latino families. Social Work Research, 30(3), $169-181$.

Retrieved

from http://www.ingentaconnect.com/content/nasw/swr/2006/00000030/00000003/art00004

Guilamo-Ramos, V., Jaccard, J., Dittus, P., \& Bouris, A. (2006b). Parental expertise, trustworthiness, and accessibility: Parent-adolescent communication and adolescent risk behavior. Journal of Marriage and Family, 68(5), 1229-1246. https://doi.org/10.1111/j.1741-3737.2006.00325.x

Guilamo-Ramos, V., Jaccard, J., Dittus, P., \& Collins, S. (2008a). Parent-adolescent communication about sexual intercourse: An analysis of maternal reluctance to communicate. Health Psychology, 27(6), 760-769. https://doi.org/10.1037/a0013833

Guilamo-Ramos, V., Jaccard, J., Dittus, P., Gonzalez, B., \& Bouris, A. (2008b). A conceptual framework for the analysis of risk and problem behaviors: The case of adolescent sexual behavior. Social Work Research, $32(1), 29-45$. 
Halpern-Felsher, B. L., Kropp, R. Y., Boyer, C. B., Tschann, J. M., \& Ellen, J. M. (2004). Adolescents' self-efficacy to communicate about sex: Its role in condom attitudes, commitment, and use. Adolescence, 39(155), 443-456. https://doi.org/10.1007/s10461-008-9468-z

Hutchinson, M. K., \& Wood, E. B. (2007). Reconceptualizing adolescent sexual risk in a Parent Based Expansion of the Theory of Planned Behavior. Journal of Nursing Scholarship, 39(2), 141-146. https://doi.org/10.1111/j.1547-5069.2007.00159.x

Hutchinson, M. K., Jemmott III, J. B., Jemmott, L. S., Braverman, P., \& Fong, G. T. (2003). The role of mother-daughter sexual risk communication in reducing sexual risk behaviors among urban adolescent females: A prospective study. Journal of Adolescent Health, 33(2), 98-107. https://doi.org/10.1016/S1054-139X(03)00183-6

Koniak-Griffin, D., \& Stein, J. A. (2006). Predictors of sexual risk behaviors among adolescent mothers in a human immunodeficiency virus prevention program. Journal Adolescent Health, 38, 297.e1-297.e11. https://doi.org/10.1016/j.jadohealth.2004.12.008

Koniak-Griffin, D., Lesser, J., Uman, G., \& Nyamathi, A. (2003). Teen pregnancy, motherhood, and unprotected sexual activity. Research in Nursing \& Health, 26, 4-19. https://doi.org/10.1002/nur.10062

Malcolm, S., Huang, S., Cordova, D., Freitas, D., Arzon, M., Jimenez, G. L., ... Prado, G. (2013). Predicting condom use attitudes, norms, and control beliefs in hispanic problem behavior youth: The effects of family functioning and parent-adolescent communication about sex on condom use. Health Education and Behavior, 40(4), 384-391. https://doi.org/10.1177/1090198112440010

Martin, J. A., Hamilton, B. E., Ventura, S. J., Osterman, M. J. K., Wilson, E. C., \& Mathews, T. J. (2012). Births: Final data for 2010. National Vital Statistics Reports, 61(1). Hyattsville, MD: National Center for Health Statistics. Retrieved from https://www.cdc.gov/nchs/data/nvsr/nvsr61/nvsr61_01.pdf

Morales-Campos, D.Y, Markham, C., Peskin, M.F., \& Fernandez, M.E. (2012). Sexual initiation parent practices, and acculturation in Hispanic seventh graders. Journal of School Health, 82(2), 75-81. https://doi.org/10.1111/j.1746-1561.2011.00669.x

Ortega, J. (2010). Applying Ecodevelopmental Theory and the Theory of Reasoned Action to understand HIV risk behaviors among Hispanic adolescents. Doctoral dissertation, University of Miami. Retrieved from http://etd.library.miami.edu/theses/available/etd-11192010-115922/unrestricted/jortega10F10.pdf

Ortega, J., Huang, S., \& Prado, G. (2012). Applying Ecodevelopmental Theory and the Theory of Reasoned Action to understand HIV risk behaviors among Hispanic adolescents. Hispanic Health Care International, 10(1), 42-52. https://doi.org/10.1891/1540-4153.10.1.42

Prado, G., Schwartz, S., Maldonado-Molina, M., Huang, S., Pantin, H., Lopez, B., \& Szapocznik, J. (2009). Ecodevelopmental x Intrapersonal risk: Substance use and sexual behavior in Hispanic adolescents. Health Education \& Behavior, 36(1), 45-61. https://doi.org/10.1177/1090198107311278

Romo, L. F., Lefkowitz, E. S., Sigman, M., \& Au, T. K. (2002). A longitudinal study of maternal messages about dating and sexuality and their influence on Latino adolescents. Journal of Adolescent Health, 31(1), 59-69. https://doi.org/10.1016/s1054-139x(01)00402-5

Sneed, C. D., Tan, H. P., \& Meyer, J. C. (2015). The influence of parental communication and perception of peers on adolescent sexual behavior. Journal of Health Communication, 20(8), 888-892. https://doi.org/10.1080/10810730.2015.1018584.

Somers, C. L., \& Ali, W. F. (2011). The role of parents in early adolescent sexual risk-taking behavior. The Open Psychology Journal, 4, 88-95. Retrieved from https://benthamopen.com/contents/pdf/TOPSYJ/TOPSYJ-4-88.pdf

U. S. Census Bureau. (2017). Hispanic origin. Retrieved from https://www.census.gov/topics/population/hispanic-origin/about.html

Villarruel, A. M. (1998). Cultural influences on the sexual attitudes, beliefs, and norms of young Latina adolescents. Journal for Specialists in Pediatric Nursing, 3(2), 69-79. https://doi.org/10.1111/j.1744-6155.1998.tb00030.x

Villarruel, A. M., Cherry, C. L., Cabriales, E. G., Ronis, D. L., \& Zhou, Y. (2008). A parent-adolescent intervention to increase sexual risk communication: Results of a randomized controlled trial. AIDS Education and Prevention, 20(5), 371-383. https://doi.org/10.1521/aeap.2008.20.5.371. 
Villarruel, A. M., Jemmott III, J. B., III, Jemmott, L. S., \& Ronis, D. L. (2004). Predictors of sexual intercourse and condom use intentions among Spanish-dominant Latino youth: a test of the planned behavior theory. Nursing Research, 53(3), 172-181. https://doi.org/10.1097/00006199-200405000-00004

Whittemore, R., \& Knafl, K. (2005). The integrative review: updated methodology. Journal of Advanced Nursing, 52(5), 546-53. https://doi.org/10.1111/j.1365-2648.2005.03621.x

\section{Copyrights}

Copyright for this article is retained by the author(s), with first publication rights granted to the journal.

This is an open-access article distributed under the terms and conditions of the Creative Commons Attribution license (http://creativecommons.org/licenses/by/4.0/). 